\title{
A Produção de Conhecimento em Psicologia: a Análise do Comportamento ${ }^{1}$
}

The knowledge Production in Psychology: The Behavioural Analysis

Resumo: $O$ artigo discute a proposta behaviorista radical de constituição da Psicologia como ciência do comportamento, destacando três conjuntos de questões: a) a noção de conhecimento com a qual opera, especialmente do ponto de vista da rejeição de princípios do positivismo lógico e adoção de uma concepção instrumental e relacional; b) uma interpretação da Psicologia como campo de saber que articula conteúdos filosóficos, científicos e aplicados e c) o programa de investigação dos fenômenos psicológicos orientado por um recorte externalista e por uma concepção selecionista de causalidade. A elaboração behaviorista radical é contrastada com concepções modernas acerca do homem, salientando-se seu alcance e seu caráter crítico e inovador na Psicologia e na cultura em geral.

Palavras-Chave: Conhecimento psicológico, behaviorismo radical, análise do comportamento.

Abstract:This paper discusses radical behaviorist approach to Psychology as a science of behavior, highlighting three sets of issues: a) the notion of knowledge adopted, particularly in its rejection of logical positivist principles, and its accordance to an instrumental and relational view; b) an interpretation of Psychology as a field of knowledge in which philosophical, scientific and applied contents are articulated; and c) a research program of psychological phenomena based on an externalist view of the subject matter and a selectionist conception of causality. The analysis contrasts radical behaviorism to modern conceptions of men, emphasizing its scope and its critical and innovatory character in Psychology and in culture in general.

Key Words: Psychological knowledge, radical behaviorism, behavior analysis.

\section{Emmanuel Zagury Tourinho}

Departamento de Psicologia Experimental, Universidade Federal do Pará.

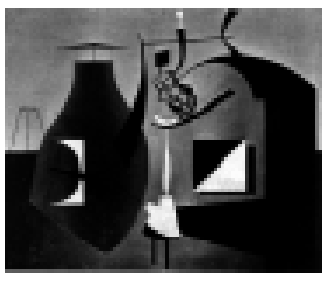

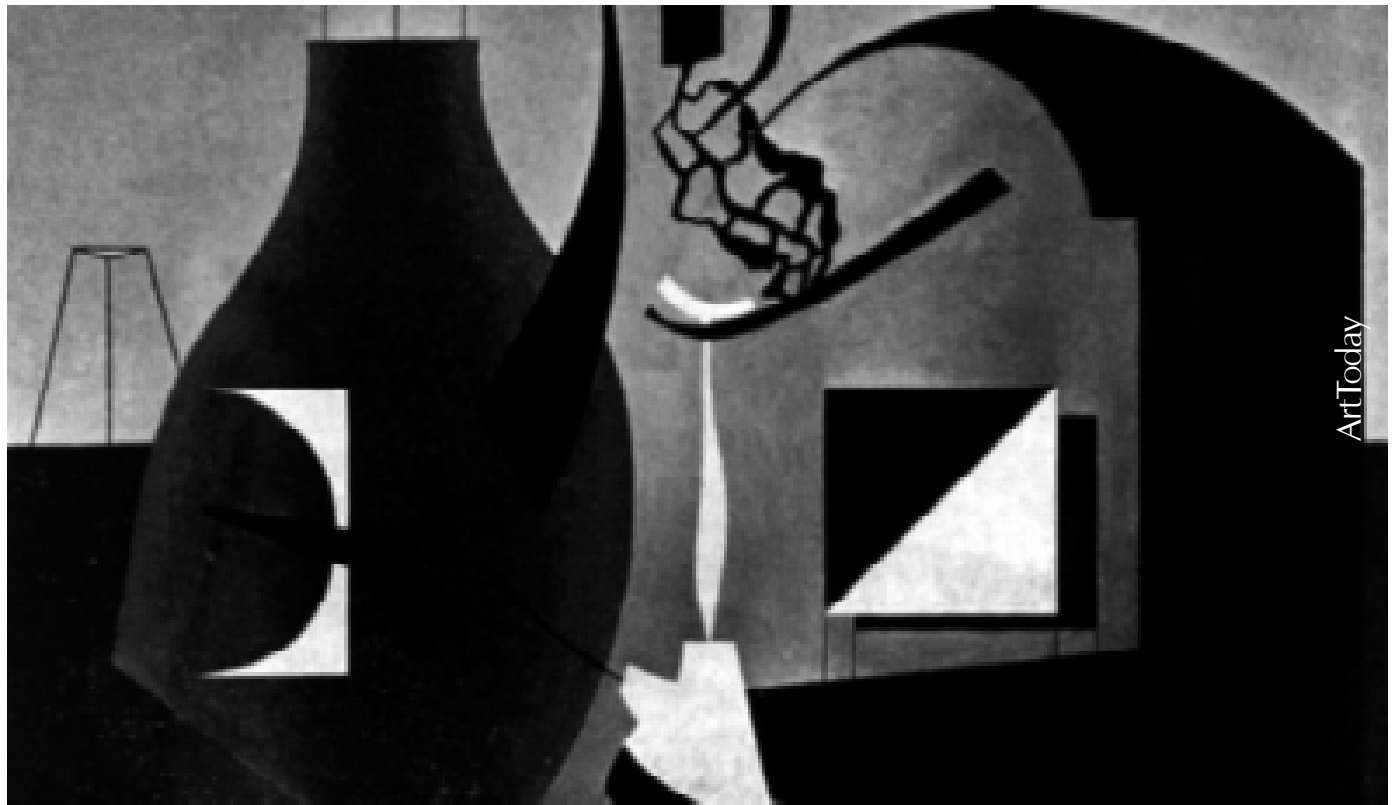

A produção de conhecimento científico é um assunto com o qual todos estão, de algum modo, familiarizados. Ainda assim, poucos concordariam sobre o que tratar em uma disciplina de metodologia científica para alunos de Psicologia, ou mesmo em uma palestra sobre o tema. Iniciamos, portanto, esclarecendo o que será abordado neste artigo. Basicamente, discutiremos o que é conhecimento, o que é a Psicologia e o que é produzir conhecimento psicológico de um ponto de vista analítico-comportamental. Com isso, queremos também deixar claro o que não será examinado. Não nos ocuparemos de técnicas ou procedimentos de investigação empregados no cotidiano científico da análise do comportamento. Não porque o assunto seja irrelevante, mas porque 
só faz sentido examiná-lo sob o pano de fundo das questões preliminares que serão privilegiadas nesta exposição.

A elaboração aqui apresentada também não deve ser tomada como o ponto de vista do conjunto dos analistas do comportamento. Da mesma forma que em outras "comunidades psicológicas", há, na análise do comportamento, certa variação (ou variabilidade) nos modos como seus membros discutem alguns problemas. Esperamos estar apresentando uma análise consistente com princípios filosóficos e conceituais da área, mas não necessariamente representativa do que qualquer analista do comportamento diria sobre o assunto.

Por último, consideramos estar nos dirigindo a leitores predominantemente não familiarizados com a análise do comportamento; evitaremos, portanto, o uso de uma linguagem técnica da área. Por outro lado, devemos antecipar que muitas das idéias apresentadas conflitam com crenças bem difundidas sobre psicólogos comportamentais e isso se deve a dois fatores que serão focalizados: primeiro, o fato de que algumas afirmações sobre os "behavioristas" são infundadas, ou seja, não correspondem realmente ao que propõem autores da área; segundo, não existe uma psicologia behaviorista, mas várias modalidades de behaviorismo, que se diferenciam substancialmente do ponto de vista de seus princípios e de seus programas de pesquisa. Nossas referências serão o behaviorismo radical proposto originalmente por B. F. Skinner e a produção da comunidade de analistas do comportamento constituída com o suporte de sua obra.

Escolhemos iniciar com uma parábola, contada pelo sociólogo Norbert Elias, em uma de suas análises críticas da concepção moderna de homem. Elias (1994) relata a seguinte parábola das estátuas pensantes:

"À margem de um largo rio, ou talvez na encosta íngreme de uma montanha elevada, encontra-se uma fileira de estátuas. Elas não conseguem movimentar seus membros. Mas têm olhos e podem enxergar. Talvez ouvidos, também, capazes de ouvir. E sabem pensar. São dotadas de "entendimento". Podemos presumir que não vejam umas às outras, embora saibam perfeitamente que existem outras. Cada uma está isolada. Cada estátua em isolamento percebe que há algo acontecendo do outro lado do rio ou do vale. Cada uma tem idéias do que está acontecendo e medita sobre até que ponto essas idéias correspondem ao que está sucedendo. Algumas acham que essas idéias simplesmente espelham as ocorrências do lado oposto. Outras pensam que uma grande contribuição vem de seu próprio entendimento. No final, é impossível saber o que está acontecendo por lá. Cada estátua forma sua própria opinião. Tudo que ela sabe provém de sua própria experiência. Ela sempre foi tal como é agora. Não se modifica. Enxerga. Observa. Há algo acontecendo do outro lado. Ela pensa nisso. Mas continua em aberto a questão de se o que ela pensa corresponde ao que lá está sucedendo. Ela não tem meios de convencer. É imóvel. E está só. $\mathrm{O}$ abismo é profundo demais. O golfo é intransponível" (pp. 96-97).

A parábola das estátuas pensantes ilustra bem como incidiu na discussão de ordem epistemológica uma concepção de homem, de acordo com a qual condições internas ou subjetivas de sujeitos particulares definem e circunscrevem suas possibilidades de conhecimento da realidade. Nessa visão, o intercâmbio humano não exerce uma função essencial, o sujeito está fechado em si mesmo; o mundo social é parte de uma exterioridade, da qual ele se distancia em seu esforço reflexivo; ainda, o status dos enunciados assim construídos sobre a natureza se define de acordo com a possibilidade de corresponderem ao que existe independentemente de sujeitos particulares e de sua interação efetiva com o mundo. O conceito de "sujeito", aqui constituído, é um correlato do conceito de "indivíduo" (elaborado na reflexão sobre as condições de realização do homem na esfera política, econômica, social e religiosa). Tanto no pensamento filosófico como em outros domínios, esse homem isolado merecerá extensa investigação de suas faculdades ou capacidades pessoais, visto serem elas a via para sua realização plena. Embora essa seja uma problematização típica da Filosofia dos séculos XVII e XVIII sua atualidade pode ser surpreendente. Há, por exemplo, clara continuidade entre aquelas noções ou crenças e o que nos fala Sennett (1988) sobre um narcisismo contemporâneo (como "distúrbio de caráter"), que impossibilita o indivíduo de atribuir significado ou valor a certas relações com o mundo, para além do que representam em termos de sensações privadamente experimentadas.

A análise do comportamento se edifica como uma modalidade de discurso psicológico crítico dessa visão de homem e da correspondente sobrevalorização do que ocorre privadamente ao indivíduo, não porque ignora a chamada "experiência subjetiva" ou deixa de reconhecê-la como constitutiva de instâncias do fenômeno comportamental, mas porque não atribui a esses eventos uma centralidade na explicação do comportamento humano; diferente disso, busca na relação do Homem com o mundo uma explicação tanto para sua experiência subjetiva, quanto para seu comportamento publicamente partilhado.
1Trabalho parcialmente financiado pelo CNPq (Processo 520062/98-1). Versóes preliminares foram apresentadas no I Simpósio O Homem eo Método e II Encontro das Escolas de Psicologia de Belo Horizonte (Belo Horizonte, abril de 2001) e no II Congresso Norte-Nordeste de Psicologia (Salvador, maio de 2001). A versão apresentada no II Congresso Norte-Nordeste de Psicologia foi divulgada no CDROM do evento. Agradeço ao Prof. Dr. Marcus Bentes de Carvalho Neto pelos comentários a uma versão preliminar do texto. 
Com essa primeira incursão no pensamento analítico-comportamental, passamos a expor como o conhecimento, especialmente o conhecimento científico, é interpretado em seu âmbito.

\section{Noção de Conhecimento e Critérios de Validação do Saber Produzido ${ }^{2}$}

As psicologias comportamentais têm relações próximas com o positivismo, como freqüentemente assinalam seus críticos. É necessário acrescentar, porém, que essas relações assumem contornos bastante variáveis. Historicamente, diferentes versões da filosofia positivista foram elaboradas; algumas delas influenciaram modalidades não coincidentes de behaviorismo.

Na primeira metade do século XX, período em que as abordagens comportamentais experimentaram grande desenvolvimento e repercussão na Psicologia, a vertente do positivismo com maior impacto no cenário filosófico era o positivismo lógico, ou neopositivismo. Os autores neopositivistas (Schlick, Carnap, Neurath, Hahn, Feigl e outros) se dedicaram a assuntos diversos, construindo uma obra filosófica difusa. O que os ligava era, principalmente, um interesse em demarcar as fronteiras entre ciência e metafísica, o que consideravam ser possível a partir de uma análise lingüística dos enunciados de um e de outro tipo. Em termos bastante gerais, os positivistas lógicos distinguiam três tipos de asserções: asserções empíricas, asserções lógico-matemáticase asserções sem sentido. A ciência deve operar com enunciados empíricos, deve ater-se à investigação do que está acessível a uma verificação pública e limitar suas leis à descrição de regularidades assim definidas. Enunciados com valor de verdade, de acordo com essa leitura, são apenas aqueles que descrevem estados de coisas empiricamente verificáveis. Essa posição colocará em dificuldades o projeto de uma ciência dos fatos psicológicos (o que, para a epistemologia positivista, não constituirá um problema), admitidos como ocorrências inacessíveis a uma observação pública direta.

O positivismo lógico influenciou certos grupos de behavioristas norte-americanos, especialmente quando, fugidos da guerra e da perseguição aos judeus, alguns membros do Círculo de Viena se mudaram para os Estados Unidos e assumiram funções acadêmicas em universidades norteamericanas. A convivência próxima entre psicólogos comportamentais e filósofos neopositivistas rendeu frutos muito evidentes, como um ensaio de Stevens (professor em Harvard, que acolheu, na época, Herbert Feigl) sobre a ciência e a linguagem científica (cf. Stevens, 1939). A modalidade de behaviorismo que incorporou preceitos do positivismo lógico na discussão sobre as feições de um projeto de Psicologia como ciência do comportamento foi, mais tarde, denominada de "behaviorismo (meramente) metodológico" (Skinner, 1945). Nas palavras do próprio Stevens (1939), “a ciência ... é um conjunto de proposições empíricas sobre as quais os membros da sociedade concordam" (p. 227) e, assim, "somente aquelas proposições baseadas em operações públicas e replicáveis são admitidas no corpo da ciência. Nem mesmo a Psicologia sabe alguma coisa sobre a experiência privada, pois uma operação para penetrar na privacidade é autocontraditória" (pp. 227-228).

No behaviorismo metodológico, o comportamento (entendido apenas como respostas públicas dos organismos) é o objeto de estudos porque é o que se presta a uma observação pública direta, atendendo aos critérios de cientificidade adotados; ele, no entanto, pode ser expressão indireta de fenômenos mais fundamentais, os fenômenos "subjetivos", que, por não cumprirem as exigências de observabilidade, não podem ser assumidos como objeto de estudos. Essa é a versão empirista de ciência que, sob a influência de preceitos neopositivistas, promove o distanciamento da Psicologia em relação aos fenômenos considerados subjetivos, ou privados. Freqüentemente, é a ela que se aplicam as críticas generalizadas para a Psicologia Comportamental como um todo. A generalização, no entanto, é incorreta, porque o discurso verificacionista do behaviorismo metodológico não é aceito pelo conjunto das abordagens behavioristas. No caso particular do behaviorismo radical, Skinner refutou repetidamente, desde 1945 (Skinner, 1945), as teses verificacionistas dos behavioristas metodológicos. No lugar da observação pública como critério de verdade, Skinner sugeria uma referência instrumental, de acordo com o qual "o critério último para a boa qualidade de um conceito não é se duas pessoas são levadas à concordância, mas se o cientista que usa o conceito pode operar com sucesso sobre seu material" (Skinner, 1945, p. 293). Para Skinner, a inacessibilidade de sentimentos e pensamentos à observação pública direta não os exclui do campo de interesses de uma ciência do comportamento. Ao abordá-los, a análise do comportamento apenas refuta a suposição de que são fenômenos "mentais", preferindo interpretálos como eventos com dimensões físicas, ainda que inacessíveis à observação pública. A abordagem científica daqueles eventos pode lançar mão de métodos não observacionais; em particular, a interpretação é postulada por Skinner como método legítimo, desde que orientada pelos conceitos já comprovados como eficazes na interpretação de fenômenos menos complexos e regulada pela eficácia em promover uma melhor interação do cientista com aqueles eventos. 
Reiterando, o behaviorismo radical admite o estudo de fenômenos como sentimentos e pensamentos (abordados com o conceito de "eventos privados"), admite a interpretação como método para lidar cientificamente com problemas dessa ordem e adota um critério instrumental de verdade na avaliação de enunciados científicos sobre quaisquer fenômenos. Trata-se, portanto, de uma versão de behaviorismo que não coincide com o behaviorismo metodológico e que não incorpora suas teses positivistas.

As relações do behaviorismo radical com o positivismo têm uma outra origem e um outro alcance. Basicamente, Skinner adota desde o início de seu programa de pesquisas (cf. Skinner, 1931/1961) uma noção de causalidade formulada em termos de relações funcionais entre eventos, o que é um modo de afastar-se de posturas mecanicistas; associado a isso, interpreta a ciência como voltada para a descrição e explicação de fenômenos, sendo essas atividades consideradas coincidentes (embora possivelmente diferenciadas quanto à abrangência - cf. SCOz, 2001), ambas correspondendo à especificação de relações funcionais. Esse modo de olhar para a ciência e para a causalidade é atribuído por Skinner, em seus primeiros textos, a Ernst Mach, um positivista que viveu de 1838 a 1916, e cuja obra citada por Skinner foi publicada ainda no século XIX (Mach, 1883/1949).

Mach foi um positivista fortemente influenciado pelo pensamento darwinista. Ele interpretava o conhecimento e as atividades dirigidas à sua construção como regulados por princípios adaptativos. Por razões que se relacionam com a história de nossa espécie, nossas "representações" do mundo são sempre organizações de nossa experiência de acordo com nossos interesses ou necessidades práticas e intelectuais. Mach supõe haver uma continuidade entre o conhecimento "prático", "primitivo", ou "pré-científico" e o conhecimento científico, sendo que o último incorpora de modo mais efetivo um "princípio de economia". De acordo com esse princípio, uma parcela cada vez mais ampla da experiência humana é organizada de modo cada vez mais simples. Assim, a ciência não provê o acesso a um conteúdo especial da experiência, mas apenas a organiza de modo mais produtivo. Observe-se que a análise de Mach implica tanto um reconhecimento da relatividade de todo enunciado científico, quanto uma naturalização dos fenômenos do conhecimento, que acaba resultando em uma valorização da observação e da experimentação como vias privilegiadas.

Como positivista, Mach considerava a ciência uma espécie de "discurso privilegiado" sobre a realidade.
No entanto, ele já se distanciava de uma perspectiva representacional, na medida em que a correspondência formal com a realidade era rejeitada; uma lei científica é apenas "a experiência economicamente ordenada de forma a estar pronta para uso" (Mach, em Lübbe, 1978, p. 94). Como assinalado por Kolakowski (1972) em uma apresentação da filosofia positivista, Mach "era profundamente convencido do caráter provisório de todo estágio da ciência e de todas as asserções científicas" (p.142). Nesse contexto, a "verdade era uma questão de promoção da adaptação de um indivíduo ou da espécie ao ambiente circundante" (Smith, 1989, p. 272); uma concepção de verdade muito próxima daquela que será veiculada no pragmatismo de William James. Assim, o positivismo de Mach já pertencia a uma tradição crítica de certos ideais positivistas "clássicos", como aqueles relacionados a uma noção representacional do conhecimento e a uma concepção universal de verdade científica.

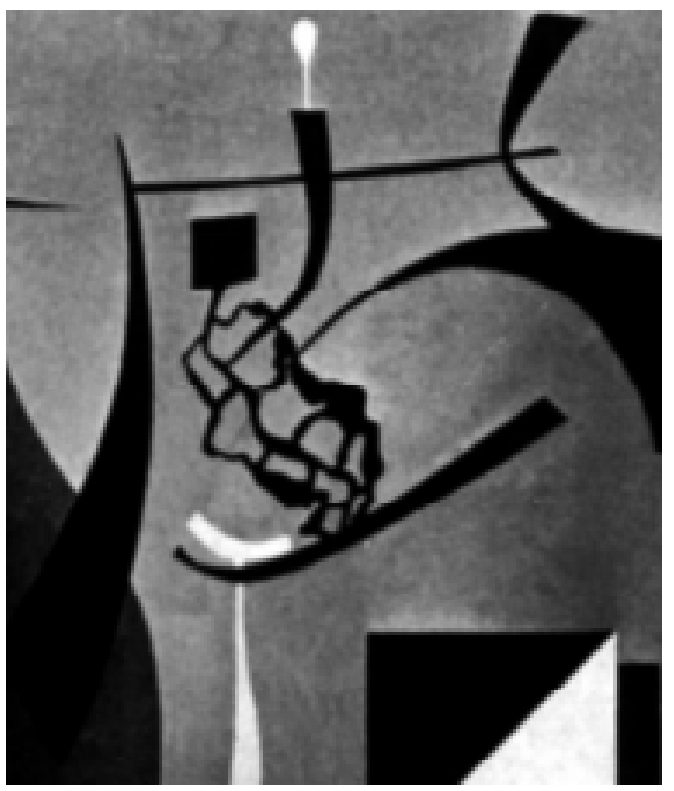

Mach supõe haver uma continuidade entre o conhecimento "prático", "primitivo", ou "pré-científico" e o conhecimento científico, sendo que o último incorpora de modo mais efetivo um "princípio de economia".

Embora o positivismo de Ernst Mach tenha influenciado o pensamento de Skinner no início de sua carreira, não se pode dizer que tenha definido os compromissos de sua ciência do comportamento. Apesar das referências de Skinner a Mach e a outros pensadores, não se deve considerar que ele buscava em qualquer filosofia a sustentação para sua ciência do comportamento. Ao contrário, desde o início, Skinner pensava que a Filosofia tinha muito a usufruir do que uma ciência psicológica produzisse sobre o comportamento humano. Com o desenvolvimento de sua obra, e especialmente com a elaboração de uma interpretação funcional para a linguagem, inclusive a linguagem científica, a abordagem do 
problema do conhecimento vai se sofisticando, sem que novas referências a pensadores positivistas sejam encontradas; ao contrário, Skinner volta a referir-se ao positivismo de um modo mais sistemático apenas em 1945, para criticar os behavioristas metodológicos e sua aceitação de preceitos do positivismo lógico. Em outras palavras, as relações do behaviorismo skinneriano com a tradição filosófica positivista são restritas, não são definitivas e não conduzem aos problemas apontados com respeito ao behaviorismo metodológico. Qualquer tentativa de caracterizar filosoficamente o behaviorismo radical com base na referência ao positivismo exigirá que se ignorem aspectos importantes da elaboração skinneriana e de outros analistas do comportamento; será, de outro modo, uma distorção do que se encontra na literatura da área. Se for necessário aproximar a análise do comportamento de um sistema filosófico particular de seu tempo, pode-se dizer que as noções de conhecimento e de verdade elaboradas por Skinner estão muito mais próximas do pragmatismo do que de qualquer outro movimento filosófico nos séculos XIX e XX. Essa relação será ilustrada a seguir.

Conhecer, para Skinner, é comportar-se de modos efetivos com respeito a uma parcela da realidade, isto é, o conhecimento não é uma posse, mas uma probabilidade de o indivíduo agir no mundo de modos produtivos (modos de ação que produzem conseqüências positivas, com ou sem um menor custo de resposta). Assim, o conceito de conhecimento diz respeito a algo que acontece no plano das relações com o mundo físico e social, e é função da história dessas relações; não descreve ocorrências internas e singulares dos indivíduos. O afastamento em relação às "estátuas pensantes", como pode ser notado, é evidente.

O conhecimento apresenta-se também sob a forma de enunciados que descrevem modos eficazes de ação no mundo, como no caso dos ditados populares e das leis científicas. As últimas descrevem não uma realidade independente dos sujeitos, mas, ao contrário, o comportamento de sujeitos que agem de modo efetivo no mundo. Enquanto comportamento, o conhecimento científico é função da história ambiental dos cientistas, especialmente sua história de interação com contingências sociais providas pela comunidade de cientistas. Essas contingências tentam limitar as influências pessoais na atividade científica, mas de modo algum colocam o comportamento do cientista sob controle estrito da natureza; são elas também que diferenciam o conhecimento científico dos outros discursos sobre a realidade. Para Skinner, o cientista, o poeta e o leigo estão em contato com um mesmo mundo (o único que existe); apenas interagem com ele de modos diferentes, por força de estarem expostos a contingências diversas (cf. Skinner, 1974).
Se o conhecimento científico é comportamento verbal sob controle de contingências sociais (as contingências dispostas por uma comunidade de cientistas) e naturais (aquela parcela da realidade com a qual o cientista interage), então ele não é "verdadeiro" em nenhum sentido especial. Para Skinner (1974), "uma proposição é 'verdadeira' tanto quanto, com sua ajuda, o ouvinte responde de forma efetiva na situação que ela descreve" ( $p$. 235); portanto, "verdadeiro" é um modo de descrever crenças que possibilitam lidar de modos efetivos com a realidade, e não há verdade absoluta.

Uma ciência do comportamento está interessada em leis gerais sobre o comportamento, no sentido de que ela dispensa especificações topográficas e fisicalistas em favor de descrições de relações funcionais entre o que um indivíduo faz e o que acontece no ambiente como conseqüência de sua ação, e está interessada em enunciados verdadeiros, no sentido de que busca descrições que capacitem o cientista para lidar de modo eficaz com fenômenos comportamentais. Qualquer apelo para além disso escapa aos compromissos ou pretensões da análise do comportamento.

William James se referia à verdade como aquilo em "que seria melhor para nós acreditar" (James, 1907/1949a, p. 77). Segundo ele, os enunciados verdadeiros "concordam" com a realidade apenas no sentido de que guiam os indivíduos de modo eficaz, isto é, "qualquer idéia que nos ajude a lidar, de forma prática ou intelectual, com a realidade ou seus pertences, que não envolve nosso progresso em frustrações, que se ajusta, de fato, e adapta nossa vida ao cenário todo da realidade, concordará suficientemente para atender o requisito. Ela será verdadeira daquela realidade" (James, 1909/1949b, pp. 304-305).

A proximidade entre as interpretações de Skinner e as teses pragmatistas de William James tem sido apontada por vários autores (e.g. Day, 1992, Malone Jr., 1975, Tourinho, 1994, 1996, Zuriff, 1980). Também a interpretação analíticocomportamental para a linguagem, que enfatiza as funções do comportamento verbal e reinterpreta as noções de significado e referência (inclusive no exame da chamada "linguagem das emoções"), tem levado a uma identificação com o pensamento do "segundo" Wittgenstein (cf. Bloor, 1987, Costall, 1980, Day, 1969, Waller, 1977). No plano das proposições filosóficas mais contemporâneas, o behaviorismo radical tem sido interpretado como consistente com o neopragmatismo de Richard Rorty (cf. Lamal, 1983, 1984, Leigland, 1999). Parece justificado considerar o pragmatismo de James, o neopragmatismo de Rorty e a análise wittgensteiniana da linguagem como contrapontos importantes de uma tradição representacional em 
Filosofia, aquela mesma contida na parábola das estátuas pensantes e em filosofias positivistas. Apontar aproximações do behaviorismo radical a esses autores (ainda que relações nesses domínios possam ser problematizadas) é um modo de indicar que, em matéria de conhecimento, ciência e verdade, a análise do comportamento não apenas rejeita o subjetivismo de certas doutrinas modernas, dirigindo sua atenção para o intercâmbio humano, como também dispensa o recurso a critérios empiristas na validação de seus enunciados.

Esclarecida a concepção instrumental e relacional de conhecimento com a qual a análise do comportamento opera, passamos a examinar como é possível definir o campo da Psicologia, no interior do qual se busca construir um conhecimento original e produtivo.

\section{A Psicologia como Área de Conhecimento e a Análise do Comportamento como Sistema Psicológico}

Há diversos modos de definir ou caracterizar a Psicologia, especialmente quando isso é feito por psicólogos, com base em seus sistemas teóricos específicos. Tentaremos falar da Psicologia de um modo que pensamos não estar comprometido com um referencial teórico particular. A Psicologia pode ser interpretada como um campo de saber, um modo particular de os indivíduos (na cultura ocidental moderna) abordarem certos conjuntos de problemas historicamente constituídos. Tem sido apontado (e.g. Figueiredo, 1991) que esses problemas dizem respeito, em geral, a sentimentos, pensamentos, emoções etc., experimentados predominantemente nas relações do indivíduo consigo mesmo, isto é, de modo privatizado. A emergência dessa ordem de problemas produz demandas de vários tipos na cultura. De um lado, é necessário tornar inteligível uma experiência que é nova e que se articula de modos complexos com uma visão de homem também original e sedutora, porém ilusória - a concepção do homem autônomo. Além disso, espera-se da Psicologia que lide com produtos dessas mudanças, dificuldades novas experimentadas pelos indivíduos em suas relações cotidianas com o mundo - e freqüentemente atribuídas ao que se passa dentro de cada um. Assim, o campo de saber da Psicologia já nasce multifacetado, não simplesmente porque é habitado por discursos conflitantes, mas no sentido de que seus conteúdos têm uma conformação variada, respondendo a demandas sociais em várias direções. A Psicologia se edifica como um campo de saber que envolve, simultaneamente: a) um esforço reflexivo sobre a natureza humana, seus problemas e suas possibilidades de realização em diferentes domínios da vida (social, material, intelectual, religioso etc.); b) uma investigação cientificamente orientada para a descoberta de regularidades dos fenômenos psicológicos (um modo de tentar apreender as novas experiências sob a forma de enunciados que incorporam os requisitos empírico-racionais da emergente ciência); c) uma profissão de ajuda, voltada para a solução de problemas humanos. Ou seja, o campo psicológico se constitui historicamente como Filosofia, como ciência e como profissão. Pensar a Psicologia desse modo ajuda na tarefa de compreender seus desenvolvimentos em muitas direções e o conflito entre discursos que são concorrentes, mas nem sempre comparáveis.

Tendo como referência essa leitura, o campo psicológico pode ser representado como um triângulo, cujos vértices correspondem àquelas três áreas (cf. Tourinho, 1999). A figura sugere de imediato a ligação ou vínculo do que pertence a uma área com o que pertence às demais. É possível, porém, ir mais longe e dizer que os fazeres da Psicologia estão localizados não exatamente em um daqueles vértices, mas em posições intermediárias entre eles, isto é, em algum ponto da área interna do triângulo. Produções consistentes em Psicologia localizam-se em pontos variados da área interna da figura, guardam relações variadas com preocupações/interesses filosóficos, científicos e aplicados, aproximam-se mais de uma do que de outra área (o que sempre possibilitará restrições de alguma ordem). Quanto mais próximo de um vértice e mais distante dos demais, maior a caracterização de um discurso como eficiente em uma direção, mas insuficiente enquanto representante da Psicologia como um todo. Por exemplo, técnicas de ajuda sem vínculos com uma produção científica e com uma reflexão filosófica consistente com nossos sistemas amplos de interpretação da realidade provavelmente terão algum sucesso na cultura, mas não serão reconhecidas como suficientes enquanto sistemas psicológicos. Terão algum sucesso porque estarão se voltando para uma necessidade real da cultura, mas não alcançarão o status de Psicologia porque suprem apenas parcialmente as demandas dirigidas à disciplina. Do mesmo modo, produções científicas que não se articulam com elaborações filosóficas consistentes, ou que não se mostram capazes de instrumentalizar para a intervenção frente a problemas humanos complexos, poderão até obter reconhecimento científico, mas não ocuparão facilmente o lugar reservado na cultura para os saberes psicológicos. Por último, interpretações psicológicas mais aproximadas de discursos filosóficos que conflitem com a lógica empírico-racional da cultura científica e/ou demonstram vínculos restritos com modelos eficazes de intervenção enfrentarão dificuldade
Assim, o campo de saber da Psicologia já nasce multifacetado, não simplesmente porque é habitado por discursos conflitantes, mas no sentido de que seus conteúdos têm uma conformação variada, respondendo a demandas sociais em várias direções. 
semelhante. Se essa interpretação estiver correta, são bem sucedidas na cultura aquelas versões de Psicologia que conjugam: a) um esforço filosófico sintonizado com as produções reflexivas contemporâneas; b) um compromisso com a incorporação de exigências empírico-racionais em seus enunciados e/ou com a interlocução com produções na área científica; c) uma busca sistemática de alternativas para a solução de problemas humanos. Como a academia é, por excelência, um espaço para o debate e validação de nossos sistemas elaborados de crenças, as psicologias bem sucedidas tornam-se psicologias academicamente validadas, em contraste com outras práticas ou explicações "psi" (como as chamadas "psicologias alternativas"), que eventualmente penetram na cultura por força de fatores diversos, mas não alcançam um reconhecimento social duradouro. Falar em psicologias academicamente validadas parece mais eficiente do que falar em psicologias científicas, considerando o que foi afirmado sobre a conformação do campo da Psicologia.

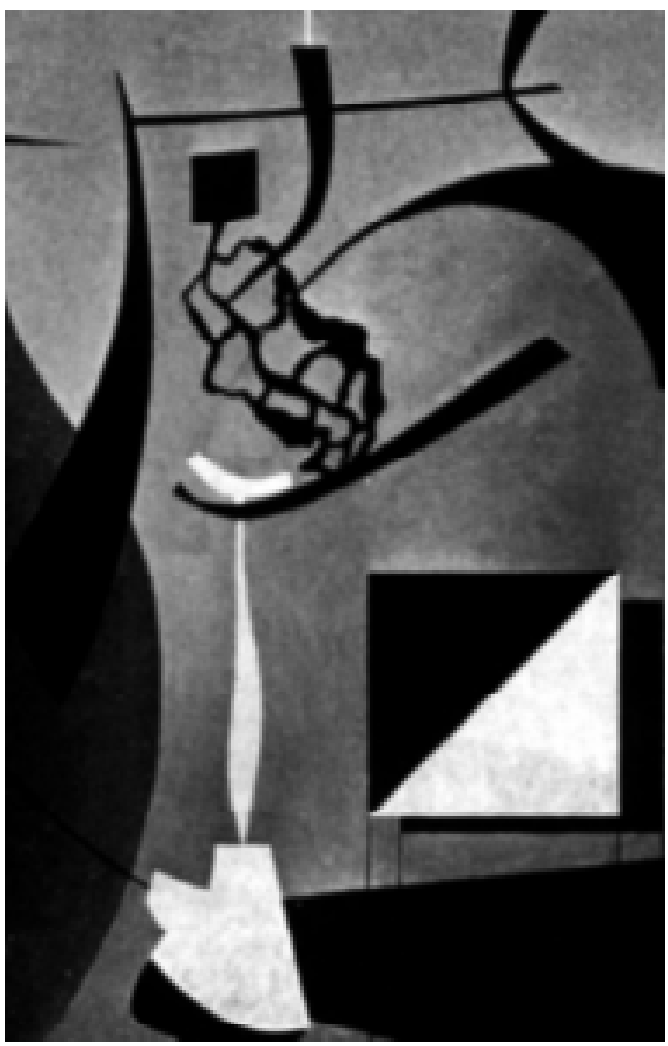

Na medida em que a análise do comportamento é considerada um sistema psicológico, sugere-se que ela é mais do que a ciência experimental referida nos manuais de Psicologia. Como sistema psicológico, a análise do comportamento é um campo de saber, no interior do qual se articulam conteúdos filosóficos, empíricos e aplicados.
Na análise do comportamento, o behaviorismo radical ocupa o lugar das produções filosóficas, reflexivas ou conceituais. Isso leva Skinner (1969) a referir-se ao behaviorismo radical como "uma filosofia da ciência que se ocupa do objeto de estudos e dos métodos da Psicologia" (p. 221, itálico acrescentado). O vértice da produção científica é representado pela pesquisa empírica, freqüentemente referida como análise experimental do comportamento, mas que, em muitas circunstâncias, é apenas descritiva, não envolvendo a manipulação de variáveis típicas da aplicação do método experimental. No vértice das produções aplicadas, encontra-se a análise aplicada do comportamento. O desenvolvimento de tecnologias de caráter analítico-comportamental para a solução de problemas conta com razoável reconhecimento, especialmente nas áreas de educação regular e especial, às quais os analistas do comportamento se dedicaram mais sistematicamente. Outras áreas também já experimentaram o avanço da análise aplicada do comportamento, como a Psicologia Institucional, a Psicologia do Esporte etc. Mais recentemente, também vem-se desenvolvendo de modo especial a terapia analítico-comportamental, voltada para a intervenção verbal face a face e distanciada do modelo de modificação do comportamento (que se mostrou eficaz na intervenção em contextos institucionais). Em algumas áreas, a aceitação de programas de intervenção analíticocomportamentais tem excepcional resultado, contrastando com a menor aceitação que a análise do comportamento tem experimentado em alguns ambientes acadêmicos, em alguma medida resultante de sua dificuldade em dialogar com outras áreas e com outras vertentes da Psicologia.

A denominação de "behaviorismo radical" para o conteúdo filosófico do sistema cultural analíticocomportamental é, por vezes, considerada inadequada, seja porque o termo "radical" se encontra associado a concepções negativas em nossa sociedade (Drash, 1988), seja porque as proposições skinnerianas precisariam ser revisadas com vistas à eliminação de inconsistências (Hayes \& Hayes, 1992). Alternativamente, tem sido proposta a adoção de expressões como "behaviorismo científico" (Drash, 1988), ou "behaviorismo contextualista" (Hayes \& Hayes, 1992). Nesse último caso, haveria um esforço para eliminar do sistema filosófico/conceitual da análise do comportamento qualquer resquício de pensamento mecanicista em favor de uma visão inteiramente consistente com uma filosofia contextualista (cf. Cavalcante, 1999).

A investigação empírica ocupa, na análise do comportamento, um lugar privilegiado; reúne os esforços de uma boa parcela de analistas do 
comportamento, e seus produtos representam a maior parte da literatura analíticocomportamental. Desse ponto de vista, pode-se mesmo falar de um desequilíbrio na distribuição da produção da análise do comportamento com respeito às três áreas citadas. Isso também explica a identificação da área com a pesquisa empírica (experimental) e a suposição, equivocada, de que analistas do comportamento se dedicam apenas precariamente a incursões filosóficas e à solução dos problemas humanos "mais profundos" ou "complexos". A suposição de confinamento da análise do comportamento ao vértice dos estudos empíricos também responde, em larga medida, pela recusa em reconhecer na disciplina as condições para pleitear a condição de "sistema psicológico". Por outro lado, tem sido apontado (Tourinho, 1999) um interesse crescente por estudos conceituais na análise do comportamento, possivelmente como decorrência, entre outros, do fato de que trabalhos desse tipo criam ou fomentam áreas de interlocução com outras teorias ou disciplinas, o que seria relevante para a sobrevivência da análise do comportamento como sistema cultural.

Como na ciência em geral e na Psicologia em particular, na análise do comportamento o trabalho conceitual é requisito para a instauração de programas de pesquisa. Esse fato é reconhecido por Skinner (cf. Tourinho, 1999) desde o início de seu trabalho, ainda que não se possa dizer que seja sempre valorizado por seus seguidores. De todo modo, pode-se ir adiante afirmando que o trabalho conceitual é não apenas condição para a instauração de programas de pesquisa, mas também para o desenvolvimento da investigação empírica. Na verdade, uma vez constituído um sistema explicativo psicológico, as diferentes áreas parecem ir permanentemente se influenciando umas às outras; a produção em um domínio vai sendo permanentemente regulada pela produção nos demais. Desse modo, as três áreas são não apenas complementares, mas, também, interdependentes. Nem sempre isso é claramente percebido:

"Do ponto de vista da percepção imediata de um pesquisador, sua investigação é tipicamente conceitual, ou empírico-experimental, ou aplicada. No entanto, essa vem a ser uma visão restrita dos processos em curso quando uma comunidade promove e valida estudos em qualquer área particular, pelos motivos de interdependência e complementaridade assinalados acima" (Tourinho, 1999, pp. 7-8).

Considerando que a análise do comportamento reivindica o status de saber psicológico e busca qualificar-se para tal com uma produção nas três áreas que definem o campo da disciplina, passaremos a apresentar alguns aspectos envolvidos no modo analítico-comportamental de interpretar e conhecer os fenômenos psicológicos.

\section{O Campo de Saber Analítico- Comportamental}

Há diversos modos de abordar as formas pelas quais a análise do comportamento se volta para a produção de conhecimento. As considerações a seguir constituem apenas uma amostra do que pode ser discutido a esse respeito, vale dizer, uma amostra com o viés de quem se dedica principalmente ao trabalho conceitual e aplicado.

A análise do comportamento pretende ocupar o lugar da Psicologia porque entende que fenômenos psicológicos são fenômenos comportamentais. O conceito de comportamento, porém, é empregado por analistas do comportamento para abordar relações. Ele não designa o que um organismo faz, mas uma relação entre um organismo e o mundo à sua volta. Por essa razão, às vezes prefere-se falar de relações comportamentais. Assim, a proposta é a de interpretar os fenômenos psicológicos como fenômenos relacionais, em outras palavras, fenômenos que dizem respeito às relações dos organismos com o seu ambiente físico e social (especialmente o ambiente social, no caso do comportamento humano).

Quando Watson inaugurou a Psicologia Behaviorista, as relações comportamentais estudadas eram as do tipo respondente ou reflexo. A investigação de processos comportamentais envolvidos em relações reflexas teve importância central para o desenvolvimento da Psicologia como ciência do comportamento, mas rapidamente mostrou-se insuficiente para dar conta da complexidade do fenômeno comportamental. Atualmente, na análise do comportamento, o paradigma operante orienta predominantemente a interpretação e investigação de relações comportamentais, mostrando-se produtivo. Relações operantes são relações do organismo com o ambiente nas quais as conseqüências das ações exercem um papel seletivo, fortalecendo ou enfraquecendo padrões de resposta. Nas relações operantes, condições antecedentes não eliciam respostas (como no reflexo); basicamente adquirem funções discriminativas ou estabelecedoras, isto é, tornam-se contextos para as relações respostasconseqüências. Comportamentos humanos complexos são interpretados como relações operantes, relações do indivíduo com o ambiente físico e social nas quais as conseqüências desempenham um papel seletivo. Como decorrência, tanto a investigação quanto as práticas 
profissionais de analistas do comportamento diante de problemas "comportamentais" (ou "psicológicos") estarão voltadas para a identificação de regularidades nas relações entre o que um indivíduo faz e aspectos antecedentes e conseqüentes às suas ações, ou seja, estarão voltadas para a identificação de relações funcionais.

A adoção de uma visão selecionista de causalidade foi inaugurada com o advento do conceito de operante (em 1937) e já significou um afastamento em relação ao modelo de causalidade mecanicista presente no conceito de reflexo. O selecionismo skinneriano sofisticou-se, em seguida, com a elaboração de um modelo que agrega uma preocupação com a multideterminação do comportamento em diferentes níveis. Para Skinner o comportamento humano é o produto simultâneo de três níveis de determinação: a filogênese (que seleciona certas características anátomo-fisiológicas, certas respostas - reflexos incondicionados - a sensibilidade às conseqüências da ação e a sensibilidade diferenciada a certos eventos ambientais); a ontogênese (na qual a imitação, modelação e modelagem produzem repertórios novos e adaptativos ao ambiente atual do indivíduo) e a cultura (que possibilita, por meio da linguagem, a aquisição de comportamentos novos sem necessidade de exposição às contingências que originalmente produziram aquele comportamento). Os programas de pesquisa em análise do comportamento ocupam-se, basicamente, das relações ao nível da ontogênese, especialmente o condicionamento operante. Nesses programas que não são ignorados os determinantes filogenéticos (portanto, não são "ambientalistas extremos" como alguns etólogos sugerem - cf. Carvalho Neto \& Tourinho, 1999), tampouco é desconhecida a importância das práticas culturais para a sobrevivência da cultura como um todo (os determinantes culturais são abordados apenas do ponto de vista de seu efeito sobre o comportamento de indivíduos particulares); simplesmente é definido um recorte de análise limitado ao plano ontogenético, tentando examinar em que medida ou de que modos operações nesse nível podem afetar o comportamento individual (em outras palavras, como solucionar problemas humanos alterando o ambiente contemporâneo dos indivíduos).

O reconhecimento da multideterminação do comportamento (mesmo quando se permanece apenas no nível ontogenético) levará o analista do comportamento a trabalhar com um determinismo probabilístico. Isso significa que é impossível lidar com todas as variáveis, das quais um comportamento é função; quando se lida com algumas daquelas variáveis pode-se apenas aumentar ou reduzir a probabilidade de um comportamento, mas não determiná-lo de modo absoluto. Para um analista do comportamento, todo comportamento humano é, em alguma medida, imprevisível, dado que o indivíduo possui uma história ambiental única e é sensível a muitas variáveis de seu ambiente físico e social. Isso é diferente, porém, de considerar impossível promover certas formas de comportamento alterando aspectos do ambiente do indivíduo, especialmente quando é possível identificar variáveis que têm relevância especial na instalação e/ou manutenção de um padrão comportamental (por exemplo, quando a coerção no ambiente escolar é crucial para a produção de respostas agressivas).

Na medida em que interpreta os fenômenos psicológicos como fenômenos relacionais, a produção de conhecimento na análise do comportamento estará voltada para a investigação de aspectos dessas relações. Como assinalado acima, descrições fisicalistas do que os organismos fazem não têm relevância especial aqui. Aspectos formais/topográficos de uma resposta precisam ser especificados apenas até onde auxiliam a identificar uma relação do organismo com seu ambiente $^{4}$.

Dado o interesse em identificar regularidades nas relações organismo-ambiente, o método experimental é o recurso privilegiado para a investigação analítico-comportamental; é por meio do seu uso que a quase totalidade da pesquisa sobre processos comportamentais básicos se desenvolve. O emprego extensivo do método possivelmente motiva muitas das críticas dirigidas à área. Há dois fatos, porém, a observar. Primeiro, o método experimental não é o único utilizado por analistas do comportamento. Muitos problemas têm um grau de complexidade que os torna inacessíveis à investigação experimental. Além disso, há circunstâncias nas quais aspectos éticos impossibilitam o seu uso. Nesses contextos, os analistas do comportamento freqüentemente se limitam à observação e descrição do comportamento ou à interpretação para lidar com fenômenos comportamentais. $\bigcirc$ segundo fato a observar é que não apenas a análise do comportamento, mas inúmeras outras abordagens psicológicas (como certas versões de cognitivismo) fazem uso do método experimental, o que também não as torna propostas restritivas de investigação. Assim, as críticas dirigidas à pesquisa experimental em análise do comportamento parecem motivadas mais propriamente por outros fatores, como a pesquisa com organismos não humanos. Como apontado por Luna (2001), "a defesa do uso de organismos inferiores na pesquisa nunca foi aceita pela comunidade de psicólogos não-analistas do comportamento e ajudou a fundamentar a rejeição" (p.146). 
O que sintetiza os modos como a análise do comportamento se volta para a investigação do fenômeno comportamental, seja na pesquisa básica, seja em situações aplicadas, é a análise funcional (cf. Cavalcante, 1999; Micheletto, 1997). Concluiremos esta parte, portanto, com um resumo do que orienta a análise funcional, não na investigação controlada de laboratório, mas na prática de intervenção do analista do comportamento. Será usada como referência a sistematização apresentada por Cavalcante (1999) em uma discussão sobre a terapia analíticocomportamental. Segundo Cavalcante, a análise funcional envolve: "a) selecionismo como modelo causal e funcionalismo como princípio de análise" (p. 40): esse princípio corresponde ao reconhecimento da "complexidade dos processos de determinação dos comportamentos humanos" (p. 40) e ao interesse pelas "funções do comportamento na produção de conseqüências ambientais" (p. 40); "b) externalismo como recorte de análise" (p. 40): aqui, a ênfase é na abordagem do fenômeno comportamental como relação do indivíduo como um todo com o ambiente, o que não exclui considerações sobre "eventos privados", mas impõe sua interpretação no contexto daquelas relações; "c) complexidade, variabilidade e caráter idiossincrático das relações comportamentais" ( $p$. 41): nesse caso, trata-se do reconhecimento de que os produtos da história ambiental são variáveis e idiossincráticos, tornando necessárias análises idiográficas; "d) critério pragmático na definição do nível de intervenção" (p. 41): na intervenção "a análise funcional desenvolve-se dentro de limites que atendem ao interesse pela solução de problemas comportamentais concretos" (p. 41); por último, "e) distinção entre alcance da avaliação e alcance da intervenção" (p. 42): se a avaliação se volta para a complexidade de eventos pertinentes às relações comportamentais de interesse, considerando, inclusive, eventos remotos e/ou inobserváveis, a intervenção lida basicamente com variáveis presentes, visando à solução de problemas.

\section{Considerações Finais}

Gostaríamos de finalizar com algumas observações sobre as posições da análise do comportamento discutidas neste trabalho. Em um artigo no qual discute as "alternativas" metodológicas disponíveis (ou não), como, por exemplo, na pesquisa psicológica, Luna (1988) chama a atenção para o que denomina de "falso conflito" entre elas. Segundo esse autor, as alternativas metodológicas podem não constituir, propriamente, "opções" diante das quais o pesquisador (nesse caso, o pesquisador psicólogo) delibera ou "escolhe". O argumento de Luna é o de que o sistema teórico no interior do qual formulamos um problema de pesquisa orienta a decisão acerca do que são os modos apropriados, ou pertinentes, de investigação. Assim, a metodologia não tem status próprio, precisando ser definida em um contexto teórico-metodológico qualquer. Em outras palavras, abandonou-se (ou vem se abandonando) a idéia de que faça qualquer sentido discutir a metodologia fora de um quadro de referência teórico que, por sua vez, é condicionado por pressupostos epistemológicos (Luna, 1988, p. 71).

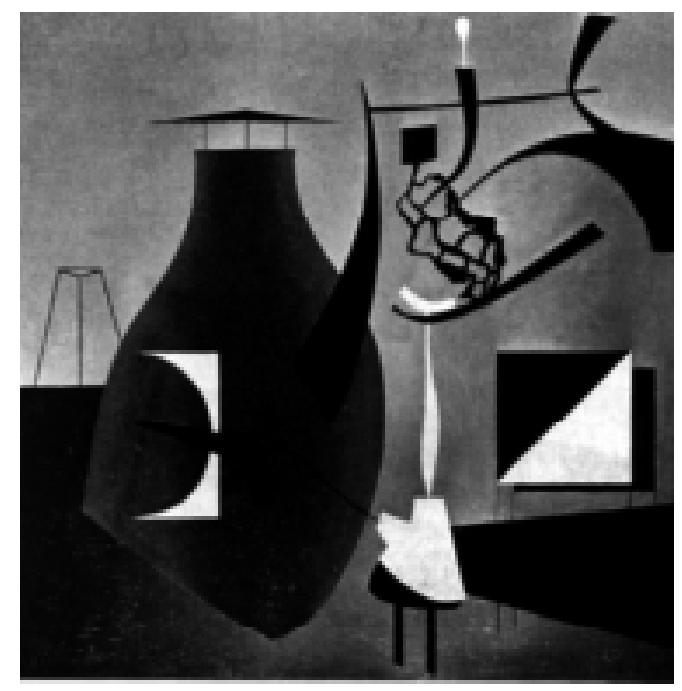

A "decisão metodológica", se é que há uma decisão metodológica, se dá antecipadamente, desde o momento em que o problema é formulado no contexto de um modelo particular de interpretação do fenômeno de interesse. Nosso sistema teórico e os supostos epistemológicos envolvidos comportam talvez "técnicas" ou "procedimentos" diferenciados, mas não recortes conflitantes dos fenômenos que se pretende estudar. Nas palavras de Luna (1988):

“O referencial teórico de um pesquisador é um filtro pelo qual ele enxerga a realidade, sugerindo perguntas e indicando possibilidades. É tão improvável que um psicanalista cogite dos efeitos da estrutura cognitiva de uma criança sobre seu desempenho, quanto um piagetiano procure levantar informações sobre a resolução do complexo de Édipo das crianças que estude" (p. 74).

Os princípios comportamentais discutidos ao longo desta apresentação constituem o "filtro" de que a análise do comportamento se serve ao olhar para os fenômenos psicológicos; eles circunscrevem as "alternativas metodológicas". Como resultado, o que a análise do comportamento tem a oferecer para a cultura é uma interpretação do comportamento humano que conflita com crenças e práticas cotidianas, mas 
que se pretende efetiva na solução dos problemas para os quais é dirigida. O que se pode indagar é se tem sido produtivo para a cultura promover essa disciplina. A resposta nos parece ser afirmativa.

O sujeito epistemológico retratado nas estátuas pensantes de Elias (1994) não sobrevive nos sistemas contemporâneos de crenças; ele sofreu críticas arrasadoras nos últimos séculos. O mesmo, porém, não ocorreu com a cultura internalista a ele associada. Continuamos a interpretar o que nos ocorre privadamente (ou subjetivamente) como essencial para a definição de nossas realizações. Aprendemos a falar da importância das nossas relações com o mundo para a construção dessa realidade mais essencial, porém nem sempre vemos essas relações como algo que merece um lugar central nas teorias ou nas intervenções psicológicas. A análise do comportamento oferece uma leitura diferente, que confere centralidade àquelas relações. Como esperamos ter ilustrado, trata-se de uma leitura refinada e produtiva.

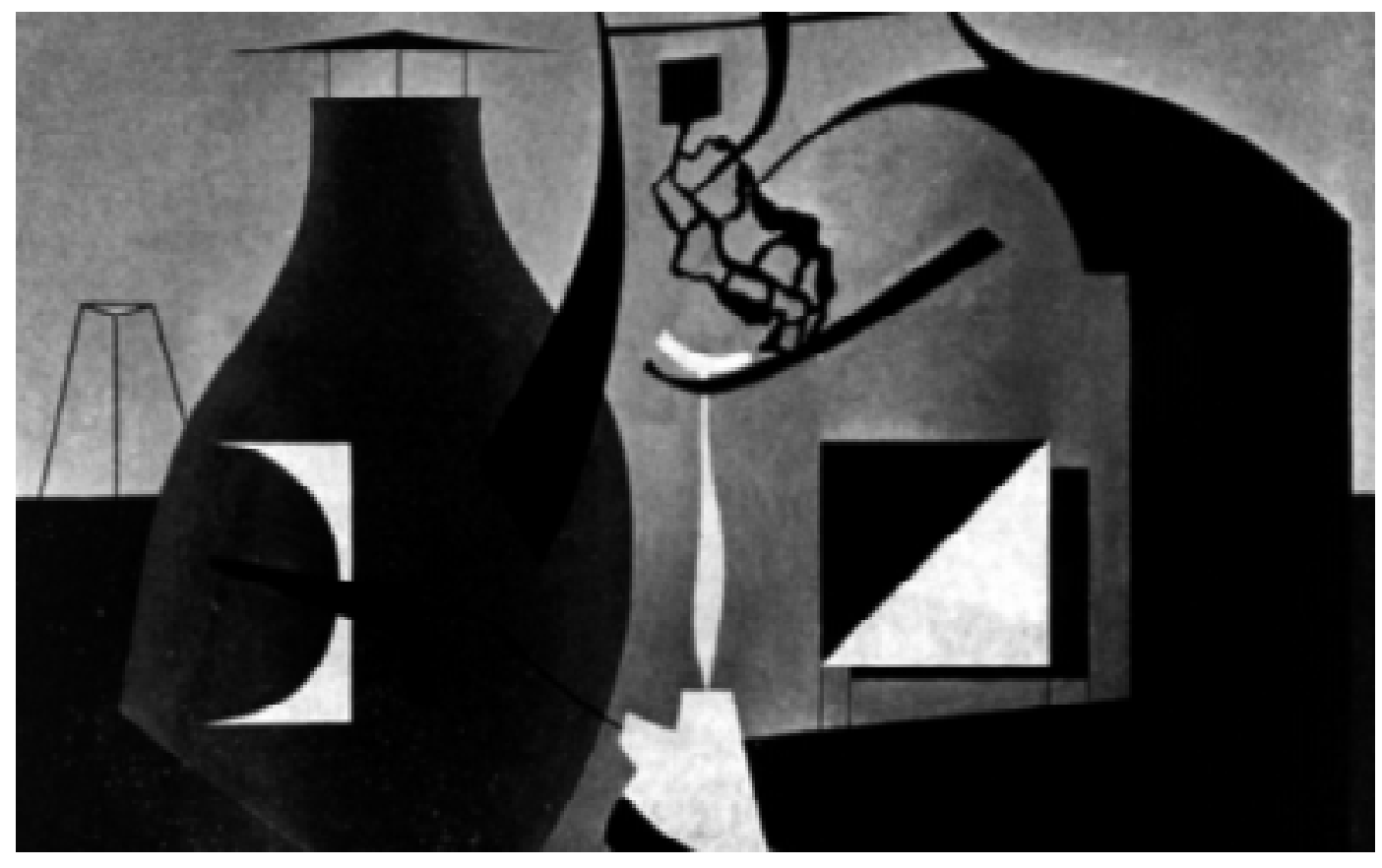


ASSOCIAÇÃO PSIQUIÁTRICA AMERICANA. Manual diagnóstico e estatístico de transtornos mentais - DSM-IV. Tradução de: D. Batista. Porto Alegre: Artes Médicas, 1995.

BLOOR, D. Wittgenstein: a social theory of knowledge. 1. reimpressão. London: MacMillan, 1987

CARVALHO NETO, M. B.; TOURINHO, E. Z. Skinner e o lugar das variáveis biológicas em uma explicação comportamental. Psicologia: teoria e pesquisa, v. 15, n. 1, p. 45-53, 1999.

CAVALCANTE, S. N. Análise funcional na terapia comportamental: uma discussão das recomendações do behaviorismo contextualista. Pará, 1999. Dissertação (Mestrado) - Programa de pós-graduação em Teoria e Pesquisa do Comportamento, Universidade Federal do Pará.

CAVALCANTE, S. N.; TOURINHO, E. Z. Classificação e diagnóstico na Clínica: possibilidades de um modelo analítico-comportamental Psicologia: teoria e pesquisa, n. 14, p. 139-147, 1998.

COSTALL, A. The limits of language: wittgenstein's later philosophy and skinner's radical behaviorism. Behaviorism, n. 8, p. 123-131, 1980

DAY, W. F. On certain similarities between the philosophica investigations of Ludwig Wittgenstein and the operationism of B. F. Skinner. Journal of the Experimental Analysis of Behavior, n. 12, p. 489506, 1969.

DAY, W. F. The historical antecedents of contemporary behaviorism In: LEIGLAND, S. (Ed.). Radical behaviorism: Willard Day on psychology and philosophy. Reno, Nevada: Context Press, 1992. p. 13-58.

DRASH, P. W. Radical behaviorism: a nonradical recommendation. The Behavior Analyst, n. 11, p. 87-89, 1988.

ELIAS, N. A sociedade dos indivíduos. Tradução de: V. Ribeiro. Rio de Janeiro: Jorge Zahar, 1994

FIGUEIREDO, L. C. M. Matrizes do pensamento psicológico. Petrópolis: Vozes, 1991.

HAYES S. C.; HAYES, L. J. Some clinical implications of contextualistic behaviorism: the example of cognition. Behavior Therapy, n. 23, p. 225-249, 1992.

JAMES, W. Pragmatism: a new name for some old ways of thinking. In: (Ed.). Pragmatism: a new name for some old ways of thinking four related essays selected from "the meaning of truth". New York: Longmans, 1949a. p. 6-301. Publicado originalmente em 1907.

JAMES, W. (1949b). Four related essays selected from "the meaning of truth". In:___. (Ed.). Pragmatism: a new name for some old ways of thinking/ four related essays selected from "the meaning of truth". New York: Longmans, 1949b. p. 303-419. Publicado originalmente em 1909.

KOLAKOWSKI, L. Positivist philosophy: from Hume to the Viena circle. Tradução de: N. Guterman. Harmondsworth: Penguin Books, 1972.

LAMAL, P. A. A cogent critique of epistemology leaves radical behaviorism unscathed. Behaviorism, n. 11, p. 103-109, 1983.

LAMAL, P. A. Getting it right: a reply to Wool folk. Behaviorism, n. 12 p. 97-98, 1984.

LEIGLAND, S. Pragmatism, science, and society: a review of Richard Rorty's objectivity, relativism, and truth: philosophical papers. Journal of the Experimental Analysis of Behavior, v. 1, n. 71, p. 483-500, 1999.
LÜBBE, H. Positivism and phenomenology: Mach and Husserl. In: LUCKMANN, T. (Ed.). Phenomenology and sociology: selected
LUNA, S. V. O falso conflito entre tendências metodológicas. Cadernos de Pesquisa, n. 66, p. 70-74, 1988.

LUNA, S. V. A crise na educação e o behaviorismo. Que parte nos cabe nela? temos soluções a oferecer? In: CARRARA, K. (Org.). Educação, universidade e pesquisa. São Paulo: Unesp, 2001. p. 143-155.

MACH, E. Desarrollo histórico-critico de la mecánica. Tradução de: J. Babini. Buenos Aires: Espasa-Calpe Argentina, 1949. Publicado originalmente em 1883.

MALONE JÚNIOR, J. C. William James and B. F. Skinner: behaviorism, reinforcement, and interest. Behaviorism, n. 3, p. 140-151, 1975

MICHELETTO, N. Bases filosóficas da noção de relação funcional. In ENCONTRO DA ASSOCIAÇÃO BRASILEIRA DE PSICOTERAPIA E MEDICINA COMPORTAMENTAL, 6., 1997, Santos. Anais... Santos: [s.n.], 1997.

SCOZ, M. C. P. Conhecer o outro: uma análise crítica do conceito de diagnóstico psicológico a partir do behaviorismo radical de B. F. Skinner. São Paulo, 2001. Dissertação (Mestrado em Psicologia Experimental) - Programa de estudos pós-graduados, Pontifícia Universidade Católica de São Paulo.

SENNEIT, R. O declínio do homem público. São Paulo: Companhia das Letras, 1988.

SKINNER, B. F. The operational analysis of psychological terms. Psychological Review, n. 52, p. 270-277; p. 291-294, 1945.

SKINNER, B. F. The concept of the reflex in the description of behavior In: SKINNER, B. F. Cumulative record - enlarged edition. New York: Appleton-Century-Crofts, 1961. p. 319-346. Publicado originalmente em 1931.

SKINNER, B. F. Contingencies of reinforcement: a theoretical analysis. New York: Appleton-Century-Crofts, 1969

SKINNER, B. F. About behaviorism. New York: Alfred A. Knopf, 1974

SMITH, L. D. Behaviorism and Logical Positivism. Stanford: Stanford University Press, 1989.

STEVENS, S. S. Psychology and the science of science. Psychological Bulletin, n. 36, p. 221-263, 1939

TOURINHO, E. Z. Behaviorismo radical, representacionismo e pragmatismo: uma discussão epistemológica do pensamento de $\mathbf{B}$. F. Skinner. São Paulo, 1994. Tese (Doutorado) - Instituto de Psicologia, Universidade de São Paulo.

TOURINHO, E. Z. Behaviorismo radical, representacionismo e pragmatismo. Temas em Psicologia, n. 2, p. 41-56, 1996

TOURINHO, E. Z. Estudos conceituais na análise do comportamento. Temas em Psicologia da SBP, v. 7, n. 3, p. 213-222, 1999.

WALLER, B. Chomsky, wittgenstein and the behaviorist perspective on language. Behaviorism, n. 5, p. 43-59, 1977.

ZURIFF, G. E. Radical behaviorist epistemology. Psychological Bulletin, 